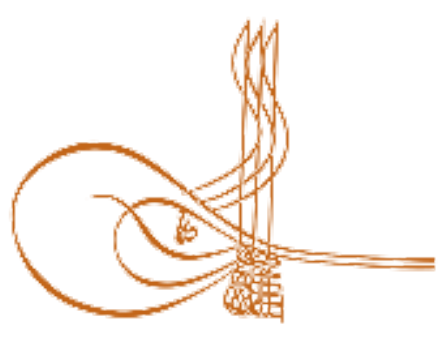

www.turkishstudies.net/education
Turkish Studies - Educational Sciences

eISSN: 2667-5609

Research Article / Araștırma Makalesi

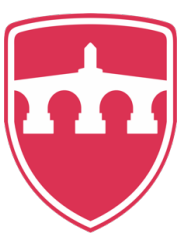

INTERNATIONAL BALKAN

UNIVERSITY

Sponsored by IBU

\title{
Öğretmenlerin Robotik Sistemlerin Kullanımına Yönelik Görüş̧leri
}

\author{
Teachers' Views on the Use of Robotics Systems
}

\author{
Sibel Açışli ${ }^{*}$
}

\begin{abstract}
The current study aims to determine what kind of activities of primary, secondary and high school teachers who have been trained in robotic systems before in their schools' activities and their opinions about the use of robotic systems. The research was carried out with 50 teachers ( 23 male and 27 female) who participated in the study voluntarily among 80 teachers who participated in robotics education organized between 2016 and 2018 years. The participants had 20 hours of robotics and programming education. As a data collection tool, a semi-structured interview form developed by the researcher by examining the related literature was used. All the participants in the study received training on robotics systems previously. The study attempted to find what kind of activities the participants carried out in their schools later with this training. Descriptive statistics (frequency and percentage distribution) was employed in the analysis of the data obtained from the study. In light of this study, the teachers' views on the use of robotic systems and how they saw robotics as a method were determined. In the end, the study revealed how much the teachers used robotics in their classes, and indicated that they were interested in and willing for the use of robotic technologies as part of curricula. To make educational robotic applications more efficient, it is expected to trainers use technology more frequently to develop themselves and to keep pace with evolving technology. It is understood that there are serious deficiencies in the development of teachers in educational robotics.
\end{abstract}

Structured Abstract: Lego applications are widely used in the learning and teaching process. It is of great importance that the instructors, who have an important role in the planning, designing and implementing learning process necessary for the robotic applications to be used in the courses, are willing and intend to use Lego robotic teaching applications, ensuring the effectiveness of the studies to be done and Lego robotic teaching applications are of great importance (Çukurbaş1 et al., 2018). In this context, this study mainly aims to determine the kind of activities that the primary, secondary and high school teachers who have previously received training on robotic systems and what kind of activities they perform in their schools and their opinions about the use of robotic systems.

\footnotetext{
${ }^{*}$ Doç. Dr., Artvin Çoruh Üniversitesi, Eğitim Fakültesi, Matematik ve Fen Bilimleri Eğitimi Bölümü Assoc. Prof. Dr., Artvin Coruh University, Faculty of Education, Department of Mathematics and Science Education ORCID 0000-0002-1144-2563

sacisli26@hotmail.com

Çalışmam etik kurul onayı gerektirmemektedir. Bu çalışma 18-20 Ekim 2018 tarihlerinde düzenlenen "Uluslararası Artvin Sempozyumu"nda sunulmuş bildirinin genişletilmiş halidir.
}

Cite as/ Atıf: Açışl1, S. (2020). Öğretmenlerin robotik sistemlerin kullanımına yönelik görüşleri, Turkish studies Education, 15(2), ...-.... https://dx.doi.org/10.29228/turkishstudies.40135

Received/Geliş: 12 December/Aralık 2019

Accepted/Kabul: 23 April/Nisan 2020

Checked by plagiarism software

Copyright (C) INTAC LTD, Turkey

Published/Yayın: 30 April/Nisan 2020

CC BY-NC 4.0 
The current study aims to determine what kind of activities of primary, secondary and high school teachers who have been trained in robotic systems before in their schools' activities and their opinions about the use of robotic systems. The research was carried out with 50 teachers (23 male and 27 female) who participated in the study voluntarily among 80 teachers who participated in robotics education organized between 2016 and 2018 years. The participants had 20 hours of robotics and programming education. As a data collection tool, a semi-structured interview form developed by the researcher by examining the related literature was used. The related literature was comprehensively reviewed while creating questions. After the literature review, a Robotic Interview Form consisting of 10 questions was created by the researcher. The form was reviewed by two field expert who has experience in robotics and programming area. The questions were reviewed according to expert opinions and then the semi-structured interview form was finalized. Interview questions were analyzed by descriptive analysis (frequency and percentage distribution were used). The participants of the research consisted of 14 IT teachers, 13 science teachers, 14 classroom teachers, 4 mathematic teachers, 1 chemistry teacher, 3 technology and design teachers and 1 teacher in social studies. 22 of the participants have 1 to 5 years of seniority, 20 to 5 to 10 years of seniority, 5 to 10 to 15 years of seniority and 3 to 15 years of seniority. Also, 46 of the participants are undergraduate and 4 are master degrees. Within the scope of current the study, it was stated that there were 30 EV3 sets, 12 renewable energy sets and $10 \mathrm{WeDo} 2.0$ Basic Sets in examined schools. According to the results, these sets are available in almost every school throughout the province. Also, participants stated that they used robotic sets after the training, $28 \%$ of them never used, $32 \%$ said they used $1-2$ times a week, $28 \%$ said they used $1-2$ times a month and $12 \%$ used sets every day. From this point of view, it was found that $56 \%$ of the participants use sets very rarely or did not at all. To make educational robotic applications more efficient, it is expected to trainers use technology more frequently to develop themselves and to keep pace with evolving technology. It is understood that there are serious deficiencies in the development of teachers in educational robotics. In a study conducted by Cüre and Özdener (2008), it was determined that teachers believe that developing technologies make learning easier, increase student and teacher success, attract students' interest, and those technological applications are necessary for teaching to be more effective, but it is also difficult to use technology in crowded classrooms. Within the scope of the study, the participants were asked how many students have you trained with robotic sets so far? According to the results, $30 \%$ of the participants stated that they did not train any students, $20 \%$ of them gave training to $1-5$ students, $16 \%$ of them gave training to 5-10 students, $20 \%$ of them gave training to $10-15$ students and finally $14 \%$ stated that they provide education to 15 or more students. Considering that $30 \%$ of teachers do not teach any students about teaching this technology to a greater number of students, it is crucial to analyze the reasons why participants do not. In the research, $78 \%$ of the participants were satisfied with using the sets, $10 \%$ said that they were not satisfied with using the sets and $12 \%$ stated that they were undecided. When the reason of why the participants are not satisfied with using the sets; 6 of them said they take a lot of time, 8 of them said the number of sets is not enough, 12 of them said I have to apply the curriculum. Kuşkaya Mumcu, Koçak Usluel (2004) found that inadequate budget facilities play an important role both in providing access to technology and sustainability of technology as the primary obstacle by teachers in terms of the barriers to the use of technology in education. As a response to the question that was you able to use the renewable energy sets with the training, you received during the study? 7 people said yes and 33 people said no; Did you also use the WeDo 2.0 Basic Kit with the training you received? 10 of the participants said yes and 25 said no. In this context, it was found that most of the teachers did not use different sets other than the set they were trained. This result also should again be questioned for reasons. Moreover, 24 of the participants who participated in the study said that 'the training I received was sufficient' and 26 people stated that 'no the training was not enough'. Within the scope of the study, $36 \%$ of the participants stated that 'I did some work outside the school to improve themselves after the training' and $64 \%$ stated that 'I did not do the additional study'. Additionally, the question of what should be done to the participants in the research to develop yourself in Robotics? was asked and 33 of the participants said 'Training should be given at advanced level, while 8 people stated that 'quarterly training should be repeated, 7 people said 'Robotic studies should be held once a month' and 2 people said 'I do not need training I can improve myself'.

Keywords: Education Sciences, Robotics, Primary School Teacher, Secondary School Teacher, High School Teacher

Öz: Bu araştırma daha önce robotik sistemler hakkında eğitim alan ilkokul, ortaokul ve lise öğretmenlerinin almış oldukları eğitimle sonrasında okullarında ne tür aktiviteler gerçekleştirdikleri ve robotik sistemlerin 
kullanımına yönelik görüşlerinin belirlenmesini amaçlayan bir çalışmadır. Araştırma 2016-2018 y1lları arasında çeşitli tarihlerde düzenlenen robotik eğitimlere katılmış olan 80 öğretmen arasından gönüllü olarak çalışmaya katılan 23 erkek 27 bayan olmak üzere toplam 50 öğretmen ile yürütülmüştür. Katılımcılar daha önceden 20 saatlik robotik ve programlama eğitimi almışlardır. Araştırmada veri toplama aracı olarak araştırmacı tarafından ilgili alanyazın incelenerek geliştirilen yarı yapılandırılmış görüşme formu kullanılmıştır. Araştırmaya katılan katılımcıların tamamı daha önceden robotik sistemler hakkında eğitim almış kişilerden oluşmaktadır. Bu araştırmada katılımcıların almış oldukları eğitimle sonrasında okullarında ne tür aktiviteler gerçekleştirdikleri tespit edilmeye çalışılmıştır. Araştırmadan elde edilen verilerin analizinde betimsel istatistikler (frekans ve yüzde dağılımı) uygulanmıştır. Bu çalışmanın 1şığında öğretmenlerin robotik sistemlerin kullanımına yönelik görüşleri ve robotiği bir yöntem olarak nasıl gördükleri belirlenmiştir. Araştırma sonunda öğretmenlerin robotiği derslerinde kullanım seviyeleri ortaya çıkarılmış olup robotik teknolojilerinin öğretim programları içerisinde kullanılmasında ilgili ve istekli oldukları tespit edilmiştir. Eğitsel robotik uygulamaların daha verimli olabilmesi için eğiticilerin kendilerini geliştirmek ve gelişen teknolojiye ayak uydurabilmek için teknolojiyi daha sık kullanıyor olmaları beklenmektedir. Eğitsel robotik konusunda öğretmenlerin kendilerini geliştirme konusunda ciddi eksikliklerin olduğu anlaşılmaktadır.

Anahtar Kelimeler: Eğitim Bilimleri, Robotik, İlkokul Öğretmeni, Ortaokul Öğretmeni, Lise Öğretmeni.

\section{Giriş}

Geçmişten günümüze kadar olan zaman içinde, ihtiyaçlar doğrultusunda gerçekleşen değişimler sonucu eğitim sistemi de çeşitli değişimlere uğrayarak değişim ve gelişim göstermektedir (Kılınç vd., 2013). Bilim ve teknolojinin her alanda gelişmesi eğitimde de teknolojinin kullanılmasını gerekli kılmaktadır (Özmen, 2004). Eğitimde teknoloji kullanımının yansımalarını birçok farklı biçimde görmekteyiz. Bu uygulamalara örnek olarak; simülasyon, arttırılmış gerçeklik, problem tabanlı online oyunlar ve robotik uygulamalar verilebilir (Çömek ve Avc1, 2016). Catlin (2012)'e göre eğitsel robotik uygulamaları öğretim amaçlı robot kullanımına dayanan bir öğretimsel stratejidir (Çukurbaşı vd., 2018). Robotik eğitimini bilinçli ve sistematik olarak yapılan ülkelerde, robotik eğitim legolar ile yapılmaktadır (Fidan ve Yalçın, 2012). Lego firması tarafindan üretilen, birçok modeli bulunan ve çeşitli yaş kategorilerine hitap eden programlanabilir Legolardan oluşan ürünlerin öğrencilere problem çözme ve üst düzey düşünme becerileri kazandırmada olumlu etkileri olduğu tespit edilmiştir (Özdoğru, 2013). LEGO eğitsel robotik uygulamalarının ilkokuldan üniversite seviyesine kadar eğitimin her aşamasında kullanılabilir olması nedeniyle bu uygulamaların öğretmenler tarafindan benimsenmesi ve bu robotik uygulamalarla öğretimi nitelikleştirmesi beklenmektedir (Çukurbaş1 vd., 2018).

Literatürde robotiğin kullanıldığı çalışmalar incelendiğinde; Zengin (2016), ilkokuldan, lise sona kadar öğrencilerin robotik sistemlerin kullanımına yönelik görüşlerinin belirlendiği çalışmasında öğrencilerin robotik teknolojilerinin öğretim programları içerisinde kullanılmasında ilgili olduklarını tespit etmiştir. Çömek ve Avcı (2016) robotik tabanlı fen öğretimi uygulamaları hakkında fen bilimleri öğretmenlerinin görüşlerini araştırdıkları çalışma sonucunda; öğretmenlerin genel olarak robotik uygulamalarının fen eğitiminde kullanılmasının öğrencilerin derse katılımlarını ve derse yönelik tutumlarını olumlu yönde etkileyeceğini ifade ettiklerini tespit etmişlerdir. Eraslan vd. (2013) çalışmalarında üstün zekâlı öğrencilerin fen eğitiminde robotik uygulamaların kullanımına ve fen bilimleri dersi deneylerine yönelik olumlu görüşlere sahip olduklarını tespit etmişlerdir. Kılınç vd. (2013) çalışmalarında BİLSEM öğrencilerinin robotik destekli fen öğretiminin öğrencilerin Fen Bilimleri dersine olan ilgilerini artırarak eğlenceli bir öğrenme ortamı oluşturduğunu tespit etmişlerdir. Çavaş vd. (2012), ilköğretim 6. ve 7. Sınıf öğrencilerine Lego Mindstorms robot kiti kullanılarak uygulama yaptıkları çalışmalarında öğrencilerin bilimsel yaratıcılıklarının ve bilimsel süreç becerilerinin geliştiğini tespit etmişlerdir. Lindh ve Holgersson (2007) robotik oyuncaklarla (legoların) yapılan etkinliklerin problem çözme etkinliklerini seven öğrencilerde başarıyı arttığını tespit etmiştir. Kasalak (2017) robotik kodlama 
etkinliklerini ortaokul öğrencilerinin eğlenceli ve ilgi çekici bulduklarını, etkinliklere katılmak için istekli olduklarını ve onların kişisel gelişimlerine olumlu katkı sağladığını tespit etmiştir.

Robotik uygulamaları derslerde kullanmak için gerekli planlama, tasarlama ve uygulama sürecinde önemli bir role sahip olan öğretmenlerin lego robotik eğitim uygulamalarını kullanmaya yönelik istekli olması, çalışmaların etkililiğinin artırılmasında büyük öneme sahiptir (Çukurbaş1 vd., 2018). Bu bağlamda çalışmada daha önce robotik sistemler hakkında eğitim alan ilkokul, ortaokul ve lise öğretmenlerinin almış oldukları eğitimle sonrasında okullarında ne tür aktiviteler gerçekleştirdikleri ve robotik sistemlerin kullanımına yönelik görüşlerinin belirlenmesi amaçlanmaktadır.

\section{Yöntem}

$\mathrm{Bu}$ araştırma daha önce robotik sistemler hakkında eğitim alan ilkokul, ortaokul ve lise öğretmenlerinin almış oldukları eğitimle sonrasında okullarında ne tür aktiviteler gerçekleştirdikleri ve robotik sistemlerin kullanımına yönelik görüşlerinin belirlenmesini amaçlayan bir çalışmadır. Araştırma 2016-2018 yılları arasında çeşitli tarihlerde düzenlenen robotik eğitimlere katılmış olan 80 öğretmen arasından gönüllü olarak çalışmaya katılan 23 erkek 27 bayan olmak üzere toplam 50 öğretmen ile yürütülmüsşür. Katılımcılar daha önceden 20 saatlik robotik ve programlama eğitimi almışlardır. Araştırmada veri toplama aracı olarak araştırmacı tarafından ilgili alanyazın incelenerek geliştirilen yarı yapılandırılmış görüşme formu kullanılmıştır. Sorular oluşturulurken literatür taraması yapılmıştır. Literatür taraması sonrasında 10 sorudan oluşan Robotik Görüşme Formu oluşturulmuştur. Form robotik eğitimi alanında çalışması olan iki uzmana sorulmuştur. Uzmanlar görüşleri doğrultusunda bu sorular gözden geçirilmiş ve sonrasında yarı yapılandırılmış görüşme formuna son hali verilmiştir. Görüşme soruları betimsel analize tabi tutularak (frekans ve yüzde dağılımı) analiz edilmiştir.

\section{Bulgular}

Araştırma kapsamında çalışmaya 23 erkek 27 bayan olmak üzere toplam 50 öğretmen katılmıştır. Bilişim teknolojileri öğretmeni 14 kişi, fen bilimleri öğretmeni 13 kişi, sınıf öğretmeni 14 kişi, matematik öğretmeni 4 kişi, kimya öğretmeni 1 kişi, teknoloji ve tasarım öğretmeni 3 kişi ve 1 kişi sosyal bilgiler öğretmeni araştırmaya katılmıştır. Katılımcılardan 22 kişi meslekte 1-5 y1llık kıdeme, 20 kişi 5-10 yıllık kıdeme, 5 kişi 10-15 yıllık kıdeme ve 3 kişide 15 yı1 ve üzeri kıdeme sahiptir. Ayrıca katılımcıların 46'sı lisans 4'ü ise yüksek lisans mezunudur.

Tablo 1. Robotik Kullanımı Soru 1'e Ait Frekans Dağılımları

\begin{tabular}{lccc}
\hline & EV3 & Yenilebilir enerji seti & We Do 2.0 Temel Set \\
\cline { 2 - 4 } & $\mathrm{f}$ & $\mathrm{f}$ & $\mathrm{f}$ \\
\hline $\begin{array}{l}\text { Okulunuz bünyesinde Robotik } \\
\text { eğitim setlerinin hangilerinden } \\
\text { kaçar adet var? }\end{array}$ & 30 & 12 & 10 \\
\hline
\end{tabular}

Tablo 1'de görüldüğü üzere "Okulunuz bünyesinde EV3 eğitim setinden kaç adet var?" sorusuna verilen cevaplardan okullar bünyesinde 30 adet EV3 seti, 12 adet yenilenebilir enerji seti ve 10 adette WeDo 2.0 Temel Seti bulunmaktadır.

Tablo 2. Robotik Kullanımı Soru 2'e Ait Frekans ve Yüzde Dağılımları

\begin{tabular}{lccccccccc}
\hline & \multicolumn{3}{c}{ Hiç } & \multicolumn{2}{c}{ Haftada Bir-İki } & \multicolumn{2}{c}{ Ayda Bir-İki } & \multicolumn{2}{c}{ Her gün } \\
\cline { 2 - 10 } & $\mathrm{f}$ & $\%$ & $\mathrm{f}$ & $\%$ & $\mathrm{f}$ & $\%$ & $\mathrm{f}$ & $\%$ \\
\hline $\begin{array}{l}\text { Robotik setlerinizi } \\
\text { kullaniyorsunuz? }\end{array}$ & ne sıklıkla & 14 & 28 & 16 & 32 & 14 & 28 & 6 & 12 \\
\hline
\end{tabular}


Tablo 2'de görüldüğü gibi “Robotik setlerinizi ne sıklıkla kullanıyorsunuz?" sorusuna katılımcıların \%28'i hiç kullanmadıklarını, \%32'si haftada 1-2 defa kullandıklarını, \%28'i ayda 1-2 defa kullandıklarını ve \%12'de setleri her gün kullandıklarını ifade etmişlerdir.

Tablo 3. Robotik Kullanımı Soru 3'e Ait Frekans ve Yüzde Dağılımları

\begin{tabular}{|c|c|c|c|c|c|c|c|c|c|c|}
\hline & \multicolumn{2}{|c|}{ Hiç } & \multicolumn{2}{|c|}{$1-5$} & \multicolumn{2}{|c|}{$5-10$} & \multicolumn{2}{|c|}{$10-15$} & \multicolumn{2}{|c|}{15 ve üstü } \\
\hline & $\mathrm{f}$ & $\%$ & $\mathrm{f}$ & $\%$ & $\mathrm{f}$ & $\%$ & $f$ & $\%$ & $\mathrm{f}$ & $\%$ \\
\hline $\begin{array}{lr}\text { Şimdiye } & \text { kadar } \quad \text { kaç } \\
\text { öğrenciye } & \text { robotik } \\
\text { setlerle eğitim verdiniz? }\end{array}$ & 15 & 30 & 10 & 20 & 8 & 16 & 10 & 20 & 7 & 14 \\
\hline
\end{tabular}

Tablo 3'de görüldüğü gibi "Şimdiye kadar kaç öğrenciye robotik setlerle eğitim verdiniz?" sorusuna katılımcıların \%30'u hiçbir öğrenciye eğitim vermediklerini, \%20'si 1-5 arası öğrenciye eğitim verdiklerini, \%16's1 5-10 arası öğrenciye eğitim verdiklerini, \%20'si 10-15 arası öğrenciye eğitim verdiklerini ve son olarak \%14’ü 15 ve üstü sayıda öğrenciye eğitim verdiklerini ifade etmişlerdir.

Tablo 4. Robotik Kullanımı Soru 4'e Ait Frekans ve Yüzde Dağılımları

\begin{tabular}{lccccccc}
\hline & & \multicolumn{2}{c}{ Evet } & & \multicolumn{2}{c}{ Hayır } & \multicolumn{2}{c}{ Kararsizım } \\
\cline { 2 - 8 } & & $\mathrm{f}$ & $\%$ & $\mathrm{f}$ & $\%$ & $\mathrm{f}$ & $\%$ \\
\hline $\begin{array}{l}\text { Setleri kullanmaktan } \\
\text { musunuz? }\end{array}$ & memnun & 39 & 78 & 5 & 10 & 6 & 12 \\
\hline
\end{tabular}

Tablo 4'de görüldüğü gibi "Setleri kullanmaktan memnun musunuz?" sorusuna katılımcıların \%78'i evet memnunum, \%10'u hayır memnun değilim derken \%12'si de kararsız olduklarını ifade etmişlerdir.

Tablo 5. Robotik Kullanımı Soru 5'e Ait Frekans ve Yüzde Dağılımları

\begin{tabular}{lcccccccc}
\hline & \multicolumn{2}{c}{$\begin{array}{c}\text { Çok fazla } \\
\text { zamanımı alıyor }\end{array}$} & $\begin{array}{c}\text { Set sayısı yeterli } \\
\text { değil }\end{array}$ & $\begin{array}{c}\text { Uygulamam } \\
\text { gereken müfredat } \\
\text { var }\end{array}$ & \multicolumn{2}{c}{ Diğer... } \\
\hline & $\mathrm{f}$ & $\%$ & $\mathrm{f}$ & $\%$ & $\mathrm{f}$ & $\%$ & $\mathrm{f}$ & $\%$ \\
\hline $\begin{array}{l}\text { Setleri } \\
\text { memnun olmama sebebiniz } \\
\text { nedir? }\end{array}$ & 6 & 12 & 8 & 16 & 12 & 24 & 0 & 0 \\
\hline
\end{tabular}

Tablo 5'de görüldüğü gibi "Setleri kullanmaktan memnun olmama sebebiniz nedir?" sorusuna katılımcıların 6'sı çok fazla zamanımı alıyor, 8'i set sayısı yeterli değil derken 12'si de uygulamam gereken müfredat var cevabını vermiştir. Ayrıca katılımcılardan bir önceki "Setleri kullanmaktan memnun musunuz?" sorusuna evet memnunum cevabını verenlerde setleri çok fazla kullanmama nedenlerini ifade etmişlerdir.

Tablo 6. Robotik Kullanımı Soru 6 ve Soru 7'ye Ait Frekans Değerleri

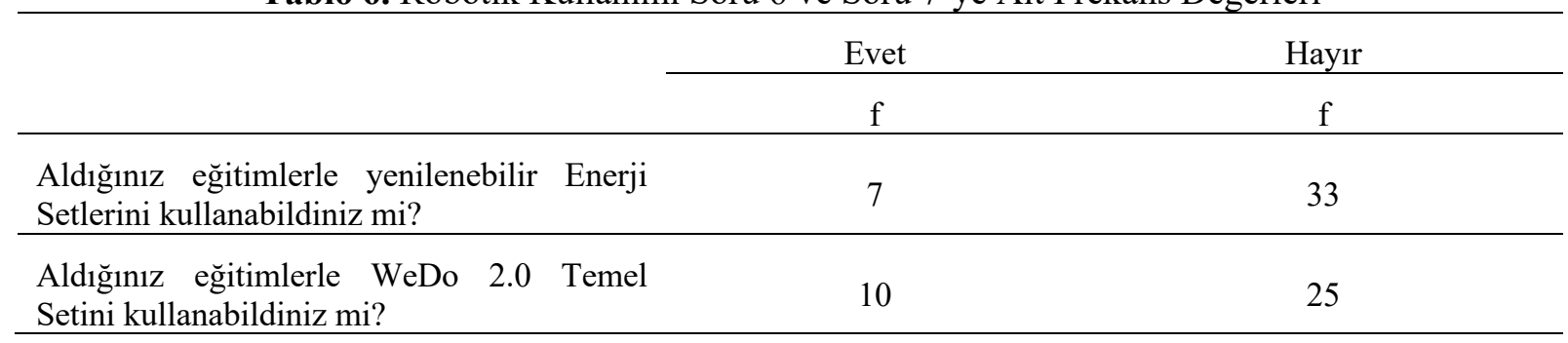


Tablo 6'da görüldüğü gibi “Aldığınız eğitimlerle yenilenebilir Enerji Setlerini kullanabildiniz mi?" sorusuna katılımcılardan 7 kişi evet, 33 kişi ise hayır cevabını; ayrıca “Aldığınız eğitimlerle WeDo 2.0 Temel Setini kullanabildiniz mi?" sorusuna katılımcıların 10'u evet derken 25'i hayır cevabını vermişlerdir.

Tablo 7. Robotik Kullanımı Soru 8 ve Soru 9'a Ait Frekans ve Yüzde Dağılımları

\begin{tabular}{lccccc} 
& \multicolumn{3}{c}{ Evet } & \multicolumn{3}{c}{ Hayır } \\
\cline { 2 - 6 } & $\mathrm{f}$ & $\%$ & $\mathrm{f}$ & $\%$ \\
\hline Aldığınız eğitim yeterli miydi? & 24 & 48 & 26 & 52 \\
\hline $\begin{array}{l}\text { Aldı̆ı̆ınız eğitimden sonra } \\
\text { geliştirmek için okul harici } \\
\text { çalışmalar yaptınız mı? }\end{array}$ & & & & \\
\hline
\end{tabular}

Tablo 7'de görüldüğ̈̈ gibi “Aldığınız eğitim yeterli miydi?” sorusuna katılımcılardan 24 kişi evet yeterliydi derken 26 kişi hayır yeterli değildi diye ifade etmişlerdir. Ayrıca katılımcılara sorulan "Aldığınız eğitimden sonra kendinizi geliştirmek için okul harici zamanlarda çalışmalar yaptınız mı?" sorusuna katılımcıların 36's1 evet yaptım derken 64'ü hayır yapmadım diye ifade etmişlerdir.

Tablo 8. Robotik Kullanımı Soru 10'a Ait Frekans ve Yüzde Dağılımları

\begin{tabular}{|c|c|c|c|c|c|c|c|c|}
\hline & \multicolumn{2}{|c|}{$\begin{array}{l}\text { Eğitimler ileri } \\
\text { seviyede de } \\
\text { verilmeli }\end{array}$} & \multicolumn{2}{|c|}{$\begin{array}{c}3 \text { ayda bir verilen } \\
\text { eğitimler } \\
\text { tekrarlanmalı }\end{array}$} & \multicolumn{2}{|c|}{$\begin{array}{c}\text { Ayda bir } \\
\text { toplanılarak robotik } \\
\text { çalışmalar } \\
\text { yapılmalı }\end{array}$} & \multicolumn{2}{|c|}{$\begin{array}{c}\text { Eğitime gerek yok } \\
\text { ben kendimi } \\
\text { geliştirebilirim }\end{array}$} \\
\hline & $\mathrm{f}$ & $\%$ & $\mathrm{f}$ & $\%$ & $\mathrm{f}$ & $\%$ & $\mathrm{f}$ & $\%$ \\
\hline $\begin{array}{l}\text { Robotik konusunda } \\
\text { kendinizi geliştirmeniz } \\
\text { için neler yapılmalı? }\end{array}$ & 33 & 66 & 8 & 16 & 7 & 14 & 2 & 4 \\
\hline
\end{tabular}

Tablo 8'de görüldüğü gibi "Robotik konusunda kendinizi geliştirmeniz için neler yapılmalı?" sorusuna katılımcılardan 33 kişi "Eğitimler ileri seviyede de verilmeli” derken, 8 kişi "3 ayda bir verilen eğitimler tekrarlanmalı" diye ifade ederken, 7 kişi "Ayda bir toplanılarak robotik çalışmalar yapılmalı" diye ifade etmiş ve 2 kişide "Eğitime gerek yok ben kendimi geliştirebilirim" diye belirtmişlerdir.

\section{Tartışma ve Sonuç}

Çalışma kapsamında robotik sistemler hakkında eğitim almış olan ilkokul, ortaokul ve lise öğretmenlerinin almış oldukları eğitimle sonrasında okullarında ne tür aktiviteler gerçekleştirdikleri ve robotik sistemlerin kullanımına yönelik görüşleri incelenmiştir.

Çalışma kapsamında katılımcıların görev yaptıkları okullar, bünyelerinde 30 adet EV3 seti, 12 adet yenilenebilir enerji seti ve 10 adette WeDo 2.0 Temel Seti bulunduğunu ifade etmişlerdir. Veriler incelendiğinde il genelinde neredeyse her okulda bu setlerden bulunmaktadır.

Araştırmada katılımcılar aldıkları eğitimden sonra robotik setleri kullanım durumlarını belirtirken katılımcıların \%28'i hiç kullanmadıklarını, \%32'si haftada 1-2 defa kullandıklarını \%28'i ayda 1-2 defa kullandıklarını ve \%12'de setleri her gün kullandıklarını ifade etmişlerdir. Buradan hareketle katılımcıların \%56'sının setleri ya çok nadir ya da hiç kullanmadıkları ortaya çıkmıştır. Eğitsel robotik uygulamaların daha verimli olabilmesi için eğiticilerin kendilerini geliştirmek ve gelişen teknolojiye ayak uydurabilmek için teknolojiyi daha sık kullanıyor olmaları beklenmektedir. Eğitsel robotik konusunda öğretmenlerin kendilerini geliştirme konusunda ciddi 
eksikliklerin olduğu anlaşılmaktadır. Cüre ve Özdener (2008) tarafından yapılan araştırmada, öğretmenlerin gelişen teknolojilerin öğrenmeyi kolaylaştırdığına, öğrenci ve öğretmen başarısını artırdığına, öğrencilerin ilgisini çekeceğine ve öğretimin daha etkili olması için teknolojik uygulamalarının gerekli olduğuna inandıkları belirlenmiş ancak bunların yanı sıra öğretmenlerin kalabalık sınıflarda teknolojiden yararlanmanın zor ve kullanmanın sorumluluklarını artırdığını düşündükleri ortaya çıkmıştır.

Çalışma kapsamında, katılımcılara şimdiye kadar kaç öğrenciye robotik setlerle eğitim verdiniz diye sorulmuş ve katılımcıların \%30'u hiçbir öğrenciye eğitim vermediklerini, \%20'si 1-5 aras1 öğrenciye eğitim verdiklerini, \%16's1 5-10 aras1 öğrenciye eğitim verdiklerini, \%20'si 10-15 aras1 öğrenciye eğitim verdiklerini ve son olarak \%14'ü 15 ve üstü sayıda öğrenciye eğitim verdiklerini ifade etmişlerdir. Öğretmenlerin bu teknolojiyi daha fazla sayıda öğrenciye öğretme konusunda öğretmenlerin \%30'nun hiçbir öğrenciye eğitim vermedikleri düşünüldüğünde katılımciların eğitim vermeme nedenlerinin analiz edilmesi büyük önem arz etmektedir.

Araştırmada katılımcıların \%78'i setleri kullanmaktan memnunum, \%10'u setleri kullanmaktan hayır memnun değilim derken \%12'si de kararsız olduklarını ifade ederken; katılımcılar setleri kullanmaktan memnun olmama sebebi olarak katılımcıların 6's1 çok fazla zamanımı alıyor, 8'i set sayısı yeterli değil derken 12'si de uygulamam gereken müfredat var demiştir. Ayrıca katılımcılardan bir önceki soruya evet memnunum cevabını verenlerde setleri çok fazla kullanmama nedenlerini ifade etmişlerdir. Kuşkaya Mumcu, Koçak Usluel (2004), teknolojinin eğitimde kullanımının engelleri konusunda öğretmenler tarafından birinci derecede en fazla engelleyen etmen olarak yetersiz bütçe olanaklarının hem teknolojiye erişimin sağlanmasında hem de teknolojinin sürdürülebilirliğinde önemli rol oynadığını tespit etmişlerdir.

Çalışma kapsamında katılımcılara aldığınız eğitimlerle Yenilenebilir Enerji Setlerini kullanabildiniz mi? sorusuna 7 kişi evet, 33 kişi ise hayır cevabını; ayrıca aldığınız eğitimlerle WeDo 2.0 Temel Setini kullanabildiniz mi? sorusuna katılımcıların 10'u evet derken 25'i hayır cevabını vermişlerdir. Bu bağlamda öğretmenlerin büyük bir çoğunluğunun eğitim aldıkları setin dışındaki setleri kullanmadıkları tespit edilmiştir. Bu sonuç yine nedenleri ile sorgulanmalıdır.

Araştırmaya katılan katılımcılardan 24 kişi aldığım eğitim yeterliydi derken 26 kişi hayır yeterli değildi diye ifade etmişlerdir. Çalışma kapsamında katılımcıların \%36'sı aldığı eğitimden sonra kendini geliştirmek için okul harici zamanlarda çalışmalar yaptım derken \%64'ü hayır yapmadım diye ifade etmiştir.

Araştırmada katılımcılara Robotik konusunda kendinizi geliştirmeniz için neler yapılmalı? Sorusu sorulmuş ve katılımcılardan 33 kişi "Eğitimler ileri seviyede de verilmeli" derken, 8 kişi "3 ayda bir verilen eğitimler tekrarlanmalı" diye ifade ederken, 7 kişi "Ayda bir toplanılarak robotik çalışmalar yapılmalı" diye ifade etmiş ve 2 kişide "Eğitime gerek yok ben kendimi geliştirebilirim" diye belirtmişlerdir.

\section{Kaynakça}

Cüre, F. \& Özdener, N. (2008). Öğretmenlerin Bilgi ve İletişim Teknolojileri (BİT) Uygulama Başarıları ve BİT'e Yönelik Tutumları, Hacettepe Üniversitesi Eğitim Fakültesi Dergisi, 34, 41-53.

Çavaş, B., Kesercioglu, T., Holbrook, J., Rannikmae, M., Ozdogru, E., \& Gokler, F. (2012). The effects of robotics club on the students' performance on science process \& scientific creativity skills and perceptions on robots, human and society. In Proceedings of 3rd International Workshop Teaching Robotics, Teaching with Robotics Integrating Robotics in School Curriculum (pp. 40-50). 
Çömek, A. \& Berkan, Avcı. (2016). Fen eğitiminde robotik uygulamaları hakkında öğretmen görüşleri. Yüksekögrrenim Üzerine.

Çukurbaşi, B., Konokman, G. Y., Güler, B. \& Kartal, S. E. (2018). Developing The Acceptance Scale of LEGO Robotics Instructional Practices: Validity and Reliability Studies. Bartın Üniversitesi Egitim Fakültesi Dergisi, 7(1), 191-214.

Eraslan, M., Şenol, A. K., Kılınç, A., Büyük, U., (2013). Ortaokulu, A., Ortaokulu, O. K., \& Abd, F. B. E. Üstün Zekalı Öğrencilerin Fen Öğretiminde Robot Teknolojisinin Kullanımına Yönelik Görüşleri.

Fidan, U. \& Yalçı, Y. (2012). Robot Eğitim Seti Lego Nxt. Afyon Kocatepe Üniversitesi Fen Ve Mühendislik Bilimleri Dergisi, 12(1), 1-8.

Kasalak, İ. (2017). Robotik Kodlama Etkinliklerinin Ortaokul Öğrencilerinin Kodlamaya İlişkin Özyeterlik Algılarına Etkisi ve Etkinliklere İlişkin Öğrenci Yaşantıları (Master's thesis, Eğitim Bilimleri Enstitüsü).

Kılınç, A., Şenol, A. K., Eraslan, M. \& Büyük, U. (2013). Robotik Destekli Fen Öğretimi: Bilsem Örneği In Internatıonal Symposium On Changes And New Trends In Educatıon (P. 65).

Kuşkaya-Mumcu, F. \& Koçak-Usluel, Y. (2004). Mesleki ve Teknik Okul Öğretmenlerinin Bilgisayar Kullanımları ve Engeller, Hacettepe Üniversitesi Eğitim Fakültesi Dergisi, 26, 91-99.

Lindh, J. \& Holgersson, T. (2007). Does lego training stimulate pupils' ability to solve logical problems?. Computers \& education, 49(4), 1097-1111.

Özdoğru, E. (2013). The Effect of Lego Programme Based Science and Technology Education on the Students' Academic Achievement, Science Process Skills and Their Attitudes Toward Science and Technology Course for Physical Facts Learning Field. Master's Thesis, Dokuz Eylül University, İzmir.

Özmen, H. (2004). Fen öğretiminde öğrenme teorileri ve teknoloji destekli yapılandırmac1 (constructivist) öğrenme. The Turkish Online Journal of Educational Technology (TOJET), $3(1), 1303-6521$.

Zengin, M. (2016). İlkokul, ortaokul ve lise öğrencilerin disiplinleraras1 eğitim \& öğretiminde robotik sistemlerinin kullanımına yönelik görüşleri. Üstün Yetenekliler Ĕgitimi ve Araştırmaları Dergisi (UYAD), 4(2). 